This disturbance of balance between the bottom vegetation and the plankton favoured the latter, resulting in an almost pure growth of the flagellate, to a concentration of $1,200,000 / \mathrm{cm}^{3}$ - giving a transparency of only $40 \mathrm{~cm}$. Owing to the exclusion of light, the growth of the Characer was finally inhibited, the dead mass yielding up its nitrates and phosphates; these, added to those bound by the plankton, probably accounted for the increase of $9.3 \mathrm{mgm}$. nitrate and $0.27 \mathrm{mgm}$. phosphate per litre in the autumn of 1938. Though all the fish died, the following arthropods were apparently unaffected : Chironomids, Mysis, Sphoroma and Carcinus. The small fish which appeared in the following year may have represented a refugee population from the freshwater affluents. In Selsø Sø, Prymnesium parvum again dominated the plankton, but only reaching half its concentration in Ketting Nor, though other phytoplankton contributed to produce the same transparency.

Experiments on the effects of the flagellate water from Ketting Nor on fishes showed that Prymnesium by itself is harmless, but a colloidal metabolite, which is retained together with the flagellate only by an asbestos filter, and separated from it by shaking a culture with charcoal, has definite toxic effects on fishes. Although the flagellate is killed at $41^{\circ} \mathrm{C}$., the poisonous effect remains after heating to $60^{\circ}$ and $80^{\circ}$, though it disappears on boiling. The poisoning results, not in hæmolysis in the gills, as previously supposed, but in a generalized nervous paralysis. The effect is permanent and cannot be cured by transferring the fish to clean water. The poison is apparently cumulative in the medium, for it has only weak effects in young cultures ; but in older cultures it is present in greater concentrations, which become maximal in the autumn. Nora G. Sproston

\section{EXPERIMENTAL FORESTRY IN SWEDEN}

TN No. 32 of that ports of the Swedish Institute 1 of Experimg Hal Forestry (1940-41) (Centraltryckeriet, 'Este A.-B., Stockholm, 1941), Erik Björkm fry" in a paper entitled "Mycorrhiza in Pine and Sprace Seedlings grown under Varied Radiation Intohsities in Rich Soils with or without Nitrate Added" gives the results of a study of the root and mycorrhiza development of young pine (Pinus sylvestris) and spruce (Picea excelsa) grown in eight different soils-most of them soils rich in nutrients -under different light conditions, with or without aviilable nitrogen added up to very high doses. These two species are commercially the most important of the timbers in the Swedish forests. The study forms part of an investigation planned by Prof. H. Hesselman, who had already briefly reported in 1939 on its general layout and main results. Some of the data reported used by the author are borrowed from a forthcoming publication by Prof. Hesselman.

The soils used are listed as follows : mull, oakwood (oakburst with sparse ground-cover of herbs and dense undergrowth of hawthorn, bird-cherry, etc.) ; mull, spruce-wood (cultivated pine forest with abundant Oxalis); mull, alderwood (alder grove (fen wood) with Urtica dioica); mull, beech-wood (beoch wood with Asperula, Cardamine impatiens, etc.) ; garden soil ; mull rich in calcium, spruce wood (spruce wood with abundant Mercurialis); mor plus sand (mixed coniferous wood with Myrtillus, etc.); mull spruce wood (closed spruce wood with mosses). The paper discusses the investigations and experiments undertaken.

In a paper by Lars-Gunnar Romell on "Studies on Pruning in Pine and Spruce", an analysis is made of some 3,000 knots in unpruned or pruned Scots pine and some 1,200 in pruned Norway spruce. In addition, data were collected on growing trees and stands. There appear to be considerable variations in the time at which knots heal over, and to some extent in the way in which the healing takes place. The analyses made display this in an interesting fashion. It is mentioned that, in one case of greenpruning of branches of spruce, an insect attack developed after the green-pruning in late spring (the best time to green-prune is late winter or early spring), all the pruned trees being attacked three weeks after the pruning by the six-toothed bark borer (Tomicos sexdentatus), a not surprising result. This is a most interesting and an important subject in its connexion with the spacing of plants in plantations, and the corresponding costs.

An interesting contribution to the discussion "On the Importance of the Ripening of the Humus in Clear-cut Areas Prior to Reafforestation" by L. Tirén describes experiments carried out in certain marked strips of cut-over forest to ascertain the results of allowing the areas to lie fallow for a varying period of years. There were two sections in one forest of which the several strips lay unplanted for six, four and two years, and the other for eight, six, four and 0 years. The object was to ascertain the ripening effects on the humus layer of the varying periods of exposure. So far, the opinion appears to be that the experiments have not lent support to the view that a certain ripening period prior to afforestation would decidedly and permanently improve the results of the afforestation. The investigations were carried out in Norrland.

\section{FORTHCOMING EVENTS}

\author{
Tuesday, July 16
}

BRITISH STANDARDS INSTITUTION (at the Institution of Mechanical Engineers, Storgy's Gate, St. James's Park, London, S.W.1), at 3.30 p.m.-Annlom General Meeting.

\section{Toy Friday, July 19} Nochemical SocIETY (in the Department of Biochemistry, Univer-
sityl Papers and Demonstrations.
Paplew Buildings, Teviot Place

Saturday, July 20

BRITISH Association (in the Hall of the British Medical Association, Tavistock Square, London, W.C.1), at 3.30 p.m.-Annual General Meetthe Pursuit of Knowledge" (Presidential Address).

\section{APPOINTMENTS VACANT}

APPLICATIONs are invited for the following appointments on or before the dates mentioned :

DISTILLERY WXERT, Government of the United Provinces, India -The Office of the High Commissioner for India, General Department, India H asu liwych, London, W.C.2 (July 20).

JUN 6 LECUURE Or LECTURER IN THE DEPARTMENT OF BOTANYThe Secrtary, Bedford College for Women, Regent's Park, London, N. 2 (July 20).

LECTURER AND AN ASSISTANT IN THE DEPARTMENT OF MATHEMATICS-The Secretary, The University, Aberdeen (July 20).

ASSISTANT LECTURER IN BOTANY AND ZOOLOGY, and a responsible LECTURER (Senior Assistant) IN PHYSIOLOGY - The Principal, Chelsea Polytechnic, Manresa Road, Chelsea, London, S.W.3 (July 20).

DEPUTY DIRECTORS IN THE BURMA VETERINARY DEPARTMENTThe High Commissioner for India, General Department, India House, Aldwych, London, W.C.2 (July 20). 